\title{
English Language Proficiency Tests and Academic Achievement: A Study on the Malaysian University English Test as a Predictor of Technical Programme Undergraduates Academic Achievement
}

\author{
Nurhazlini Rahmat (Corresponding author) \\ Multimedia University, Malaysia \\ E-mail: nurhazlini.rahmat@mmu.edu.my \\ Lau Sing Min \\ Universiti Putra Malaysia \\ Nur Atiqah Md. Sungif \\ Universiti Putra Malaysia \\ Farah Nabillah Mior Yusup \\ Universiti Putra Malaysia
}

Doi:10.7575/aiac.alls.v.6n.1p.114

URL: http://dx.doi.org/10.7575/aiac.alls.v.6n.1p.114
Received: 25/09/2014

Accepted: 28/11/2014

\begin{abstract}
In the Malaysian education system, English has always played an important role. In acknowledging its importance, Malaysian University English Test (MUET) has been introduced to enable continued emphasis on this role. MUET has been made compulsory for those who wish to pursue a first degree programme in local universities. This study aims to examine the relationship between English language proficiency test (as measured by MUET bands) to predict the undergraduates academic achievement (as measured by Cumulative Grade Point Average score). It also aims to determine the recommended MUET band as an entry requirement for prospective technical programme undergraduates in Universiti Putra Malaysia (UPM). The study was carried out among 225 final year undergraduates of five different faculties in UPM, namely Faculty of Engineering, Faculty of Forestry, Faculty of Biotechnology and Biomolecular, Faculty of Food Science and Technology, and Faculty of Veterinary Medicine. The data used were obtained by administering a brief questionnaire and were quantitatively analysed using Statistical Package for Social Science (SPSS) version 19. The study revealed that there is a medium positive correlation between English language proficiency and academic achievement where students who have scored higher bands for MUET are the ones who obtained higher CGPA in their study. Based on the findings, it is recommended that UPM and other local universities make changes towards the minimum MUET entry requirement to help prospective undergraduates excel in their academic study.
\end{abstract}

Keywords: English language proficiency, academic achievement, technical programme, MUET, CGPA

\section{Introduction}

In this global era, English language plays an important role in the pursuit of knowledge. The English Language is a native language in numerous developed countries, such as the United Kingdom and the United States and it is also regarded as the international language of the world. In Malaysia, English language is one of the languages spoken by its people; however it is a second language for most Malaysians. With that, English language has been implemented in the education system starting from the primary level.

The Malaysian University English Test (MUET) has been introduced in the Malaysia educational system in 1999 (Malaysian Examinations Council, 2006). The purpose of MUET is to assess students' level of English language proficiency before they pursue their tertiary education. To date, MUET is a prominent examination that spells out one's English proficiency. The MUET syllabus seeks to consolidate the English language ability of pre-university students to enable them to perform effectively in their academic pursuits at tertiary level, in line with the aspirations of the National Education Philosophy (Malaysian Examination Council, 1999, p.11). With the existence of MUET, it has become a prerequisite requirement for students who want to enter public colleges and universities.

The MUET examination measures the four skills of language learning, which are listening, speaking, reading and writing: Listening (800/1), Speaking (800/2), Reading (800/3), and Writing (800/4). The results for this examination are graded from Band 1 to Band 6, with Band 6 being the highest and Band 1 being the lowest. Students' overall result 
for all four language components in MUET identifies their proficiency level and also determines the possibilities of courses they would like to pursue in the tertiary level. Currently, to enter public universities, students only need to have the minimum of Band 1 in MUET. However, in the 2015 Budget, under Measure 8: Enhancing Graduates Employability, Prime Minister of Malaysia, Dato' Sri Mohd. Najib bin Tun Abdul Razak has announced that starting 2015, the minimum English entry requirement for public institutions of higher learning admission will now be made according to field of study, and no longer the minimum Band 1 in MUET as currently required. The reason to increase MUET's score for public university entrance requirement is to address the increased number of unemployment rate among our graduates and to instill self-confidence and also to sharpen their English skills. Hence, with the announcement made, the minimum MUET band for IPTA's Arts and Social Science programmes will now be made Band 2, Science, Technology, Engineering and Mathematics programmes admission is Band 3, and Medical and Law programmes admission is Band 4.

Technical programmes are offered in many colleges and universities to meet the increasing demand for technicians, paraprofessionals, skilled craft workers, specialised clerical workers for employment in the work industry, business, government services, and many other professions. According to Foks (1990), education and training in all countries cannot rely on the traditional methods only in regards to meeting the needs and demands of students, industry and governments. Malaysia is a fast developing country and to support the growth of Malaysia's industrial sector, it needs a highly skilled workforce. To fulfill this need, the institutes of higher learning have developed many vocational and technical training institutes. Carter and Gribble (1994) considered vocational education and technical training are learning activities which can contribute to successful economic performance and tangible economic and social gains. It is therefore of great importance that students are given the chance to be educated in these fields of study. In order for them to be able to gain knowledge, there needs to be a certain level of proficiency in the English language. Without the proper grasp of the language, learning is not fully achieved.

Considering the concern that technical students must have a language competency to experience total quality in their academic learning, this study aims to investigate the relationship between the technical programme students' MUET bands and their CGPA scores. It also aims to determine the recommended MUET band as an entry requirement for prospective technical programme undergraduates in UPM. This study will provide insight on the importance of learning the English language and its relation to one's academic achievement.

\section{Language Proficiency Tests as Predictors of Academic Performance}

In Malaysia, a study by Abd. Samad et al. (2008) examined the ability of the MUET bands to predict students' academic success as measured by their composite CGPA. In the study, the researchers examined 52 third year TESL undergraduates who were studying in a local university. The finding showed a lack of evidence with regards to the validity of MUET as a predictor of academic achievements.

According to Abd Samad (2010), although MUET measures the four major skills in the English language, careful thought should be given to the testing of the speaking skill. Some students might perform better in the English listening, writing and reading examinations, but when it comes to the speaking aspect, they do not have the fluency. Moreover, when it comes to English language tests in Malaysia, there are several limitations that should be considered especially in comparing the students' academic achievement with their language proficiency.

There are several limitations of a test that have been highlighted by Bachman (1990), which include the subjectivity and incompleteness. Every test, including MUET has its own subjectivity, especially in grading the essay format test which involves writing skill. The subjectivity of tests is normally found in the content that is to be tested. Sometimes, the subjectivity could be due to other factors such as, the mood of the examiner who examines the paper or the creative answers given by the students. Meanwhile, incompleteness means the student's inability to perform well in exam due to several factors, such as time constrain and the physical setting which will restrict the students to demonstrate their true abilities in the exam. If the students did not score well in the exam, it does not mean that they do not have the knowledge, but they are actually restricted by a lot of other factors as well. These limitations simply mean that it will be difficult for language tests to have the perfect accuracy in measuring the language skills.

Meanwhile, a study carried out by Nopiah, et al. (2011) who looked at the relationship between MUET results and the students' academic performance found that MUET has a higher correlation with students' academic performance. Similarly, Juliana and Abu Bakar (2013) investigated the accuracy of MUET as a predictor of learners' academic performance. The study which focused on the ESL undergraduates concluded that MUET has moderate influence on students' academic performance. On another similar study, Rethinasamy and Chuah (2011) reported on the predictive validity of MUET as a measure of undergraduates' English language proficiency and the appropriateness of the MUET cut-off bands for placement purposes. The study validated MUET as students' language ability measurement and proposed the revisit of the existing MUET cut-off band for improvement.

In the international level, there are several tests used to measure the level of English language proficiency among learners. The two widely used tests are TOEFL (Test of English as a Foreign Language) and IELTS (International English Language Testing Service). International researchers have also conducted several predictive validity studies to determine the relationship between English language Proficiency and academic achievements. Wilson and Komba (2012) investigated the link between English language proficiency and students' academic results. They highlighted that there is a weak positive relationship between English language proficiency and students' academic achievement. 
On the other hand, the study by Stephen, Welwan and Jordaan (2004) who investigated the impact of English language proficiency on academic success of students in Africa indicated that there is a sound association between language proficiency and academic success. Similar to the research conducted by Stephen et.al. (2004), Kong, Powers, Starr and Natasha (2012) looked at the aspect of English language learning and academic performance among ELS learners. Different than the previous mentioned research, Kong and the team focused on middle-school learners. Based on the study, they arrived at the consensus that English language proficiency is interrelated with students' academic achievement as they considered the low language proficiency cause a barrier to learning and impede students' academic success.

Interestingly, the research conducted by Abdirahman, Abdullahi and Mohamed Said (2013) highlighted a different outcome. These researchers revealed that English language proficiency has insignificant positive relation to students' achievement in learning. Hence, they concluded that there is no significant impact of English language proficiency on students' academic achievements.

In terms of the technical field, a study conducted by the Computer Sciences and Information Technology Students in University Malaya had shown that most MUET candidates obtained Band 3 and Band 4 for the test (Moon, 2004). This is also reflected in the report by Malaysian Examinations Council $(2006 ; 28-29)$ where it is stated that the achievement of science candidates (which includes technical students) was much better compared to arts students with the majority of science candidates obtained Band 4 in MUET (37.6\%), followed by Band 3 (33.5\%).

Nopiah, et al. (2011) concluded in their study that apart from MUET, there is another factor that affects CGPA, which is called loading hour. Apart from that, it is found that a good command of English in the entry level can really influence students' academic performance, especially during the final year in the university.

Aina and Olanipekun (2013) researched on the effects of English language on the academic performance among Physics and Computer Science undergraduates in Nigeria. They found out that there was a negative relationship between the English language paper results and students' performance in their Physics and Computer Science studies. The research suggested that English language has no influence on students' academic performance.

With the numerous studies conducted throughout the years, it can be seen that many have shown the positive relationship between English language proficiency tests and academic achievement. However, as shown, there have been some contrasting studies where proficiency tests are found to have no relation to academic performance. Also, there have been little known studies in terms of the technical programmes when it comes to this area of study. With that, this study would shed some light onto the relationship between MUET band and CGPA when it comes to the technical programme undergraduates in UPM.

\section{Methodology}

This study was conducted among final year technical programme undergraduates in UPM with a sample of 225 participants randomly selected. The technical programmes in UPM are administered by eight faculties which are Faculty of Agriculture, Faculty of Biotechnology and Biomolecular, Faculty of Computer Science and Information Technology, Faculty of Economics and Management, Faculty of Engineering, Faculty of Food Science and Technology, Faculty of Science, and Faculty of Veterinary Medicine,

From the eight faculties, five faculties were chosen at random for the collection of data, namely Faculty of Engineering, Faculty of Forestry, Faculty of Biotechnology and Biomolecular, Faculty of Food Science and Technology, and Faculty of Veterinary Medicine. From the selected five faculties, 225 final year undergraduates are chosen at random to participate in the study as represented in the table 1 below.

\begin{tabular}{lc} 
Table 1. Faculties & \\
\hline \multicolumn{1}{c}{ Faculties } & Percentage \\
\hline Faculty of Engineering & 29.3 \\
Faculty of Forestry & 12.0 \\
Faculty of Biotechnology and Biomolecular & 11.6 \\
Faculty of Food Science and Technology & 23.1 \\
Faculty of Veterinary Medicine & 24.0 \\
Total & 100.0
\end{tabular}

The participants' MUET band and CGPA are collected through the use of questionnaires. The collected data are then being correlated using Pearson's Correlation to see if there would be a relationship between MUET bands and CGPA scores.

\section{Findings and Discussion}

SPSS version 19 was used to analyse the collected data. The students were asked to fill in a questionnaire that gathers their MUET and CGPA results. 
The students' academic achievement is represented in Table 2 which shows the classification of degree that distinguishes the academic achievements of final year undergraduates. It is observed that that only $22.7 \%$ of them are placed in the first class range (with CGPA of 3.750-4.000), followed by 66.7\% in the second class upper (with CGPA of 3.000-3.749), and the remaining $10.6 \%$ in the second class lower range (with CGPA of 2.250-2.299).

Table 2. Classification of Degree

\begin{tabular}{lc}
\hline \multicolumn{1}{c}{ Classification } & Percentage \\
\hline First Class (3.750-4.000) & 22.7 \\
Second Class Upper (3.000-3.749) & 66.7 \\
Second Class Lower (2.250-2.999) & 10.6 \\
Total & 100.0 \\
\hline
\end{tabular}

Table 3 shows the MUET results of the samples with most of the students scoring a Band $3(53.8 \%)$. This is then followed by a $32 \%$ of the sample scoring Band 4 . This shows that most of the students are scoring at the range of Band 3 and 4 which indicate an average or slightly above average level of English language proficiency.

\begin{tabular}{lrc} 
Table 3. MUET Results & & \\
\hline Band & $\mathrm{N}$ & Percentage \\
Band 2 & 20 & 8.9 \\
Band 3 & 121 & 53.8 \\
Band 4 & 72 & 32.0 \\
Band 5 & 11 & 4.9 \\
Band 6 & 1 & 0.4 \\
Total & 225 & 100.0
\end{tabular}

In table 4, it can be seen that the student who scored a Band 6 in MUET is within the CGPA range of 3.50-4.00. This is followed by 11 students who scored a Band 5 in MUET with CGPA range of 3.00-4.00. At MUET results of Band 4, out of the 72 students, more than half (48) scored within the CGPA range of 3.50-4.00 followed by 20 students within the range of 3.00-3.49, and 4 students within the range of 2.50-2.99. This result is similar to the study done by Moon, T. S. and Siew, H. O., (2004) who found that more than half of the students who were in band 4 scored within the CGPA range of 3.01-3.69.

Meanwhile, a total of 20 students scored Band 2 in MUET placed themselves in all three CGPA's category with 6 of them within the 2.50-2.99 range, 12 of them within the CGPA range of 3.00-3.49, and 2 of them within 3.50-4.00. Among the 121 students who have Band 3 as their entry requirement, 58 of them scored the CGPA range of 3.00-3.49, followed by 48 of them with 3.50-4.00 CGPA range.

Overall, it can be concluded that students ( 84 of them) who have scored higher bands in MUET (Bands 4, 5 and 6 ) are mostly in the CGPA range of 3.00-4.00, with only 4 out of 84 scoring within the $2.50-2.99$ range. In other words, students who obtained good bands in MUET will be able to score good CGPA. This is supported by the claim made by Stephen, Welwan and Jordaan (2004) where they have proven in their study that there is a sound relationship between language proficiency and academic success.

Table 4. MUET and CGPA Cross tabulation

\begin{tabular}{lccc}
\hline MUET & \multicolumn{3}{c}{ CGPA } \\
& $2.50-2.99$ & $3.00-3.49$ & $3.50-4.00$ \\
Band 2 & 6 & 12 & 2 \\
Band 3 & 15 & 58 & 48 \\
Band 4 & 4 & 20 & 48 \\
Band 5 & 0 & 2 & 9 \\
Band 6 & 0 & 0 & 1 \\
Total & 25 & 92 & 108 \\
\end{tabular}


The findings from Table 4 are supported by the Pearson Correlation shown in Table 5. The correlation coefficient (r) between CGPA and MUET is shown to be .368. This shows a medium positive correlation between the samples' English language proficiency and academic achievement. The finding is similar to the findings of Juliana and Abu Bakar (2013) who agreed that MUET has a moderate influence on students' academic performance and Zulkifli, et al. (2011) who reported that the students' academic performance has a high correlation with MUET. It is also in line with the study done by Nopiah, et al. (2011) who claimed that students with a good command of English language at the entry level will be able to perform better academically.

Table 5. Correlation Analysis of CGPA \& MUET

\begin{tabular}{llcc}
\hline \multicolumn{2}{c}{ Correlation } & CGPA & MUET \\
CGPA & Pearson Correlation & 1 & $.368^{* *}$ \\
& Sig. (2-tailed) & & .000 \\
& $\mathrm{~N}$ & 225 & 225 \\
\hline \multirow{2}{*}{ MUET } & Pearson Correlation & $.368^{* *}$ & 1 \\
& Sig. (2-tailed) & .000 & 225 \\
& $\mathrm{~N}$ & 225 & \\
\hline
\end{tabular}

**. Correlation is significant at the level 0.01 level (2 tailed)

With reference to the findings, there should be some changes made to the MUET requirement for students who wish to pursue their tertiary education in UPM as illustrated in Table 6. Currently, only two faculties involved in this study, Faculty of Engineering and Faculty of Veterinary Medicine have set a MUET entry requirement of Band 3 while the other three faculties set a general minimum MUET entry requirement of Band 1. While it has shown to be effective for undergraduates from the Faculty of Engineering and Faculty of Veterinary Medicine to enter with a minimum of Band 3, other faculties should consider changing their minimum MUET requirement as well. Based on findings, it is advisable that the other faculties follow suit and set a minimum of Band 3 as an entry requirement.

Table 6. MUET Entry Requirement

\begin{tabular}{lcc}
\hline Faculty & Current & Recommended \\
Faculty of Engineering & 3 & 3 \\
Faculty of Forestry & 1 & 3 \\
Faculty of Biotechnology and Biomolecular & 1 & 3 \\
Faculty of Food Science and Technology & 1 & 3 \\
Faculty of Veterinary Medicine & 3 & 3 \\
\hline
\end{tabular}

The changes in the MUET entry requirement will benefit students in their academic endeavour as the undergraduates themselves noted MUET did contribute to their academic achievement. This is showcased in Table 7 where the highest CGPA (3.50-4.00) achievers are in favour that MUET contributes to their academic achievement.

Table 7. MUET as a contributive factor in academic achievement

\begin{tabular}{lccc}
\hline & $\begin{array}{c}\text { Academic } \\
\text { Achievement }\end{array}$ & Agree & Disagree \\
\hline CGPA & $2.50-2.99$ & 16 & 9 \\
& $3.00-3.49$ & 50 & 42 \\
& $3.50-4.00$ & 62 & 46 \\
Total & & 128 & 97 \\
\hline
\end{tabular}




\section{Conclusion}

The deterioration of the language and its relation with academic achievement has been a main concern for educators in the country. Therefore, with the purpose of MUET to assess students' level of English language proficiency in order for them to pursue their tertiary education, more emphasis should be placed on the learning of the language. It has been noted that more studies were carried out in the area of the non-technical field as compared to the technical field. As such, this study attempts to highlight the correlation between MUET and CGPA within technical programme students. Based on the data presented in this paper, it shows that there is a medium positive correlation between the undergraduates' English language proficiency and academic achievement. In order words, technical programme undergraduates who have higher English language proficiency are found to score better in their tertiary education. This study also aims to recommend a more suitable minimum MUET entry requirement for the technical programmes faculties. According to the data collected, it is strongly recommended that the university makes changes towards the minimum MUET band required to enter the university. These findings provide insight on how UPM and other universities can make changes to their minimum entry requirement when it comes to the students' English language proficiency.

\section{References}

Abd Samad, A. (2010). Essentials of Language Testing for Malaysian Teachers. Revised Edition. Kuala Lumpur, MA: Aslita Sdn. Bhd.

Abd Samad, A., Syed Abd Rahman, S.Z. \& Yahya, S.N. (2008). Refining English language tests for university entrance: A Malaysian example. Asian Journal of University Education. Vol 3(1), 57-71.

Aina, J. K. \& Olanipekun, S. S. (2013). Effects on English language on academic performance in physics and computer science among college of education students. American International Journal of Research in Humanities, Arts and Social Sciences, 114- 117.

Carter, E. \& Gribble, I. (1994). Work-based Learning: A discussion paper. Office of the State Training Board, Melbourne, 5 .

Foks, J. (1990). Technical and vocational education and training by distance. Report of an International Conference Convened by the Commonwealth of Learning. Part II: Keynote Papers. City Polytechnic, Hong Kong.

Juliana, O. \& Abu Bakar, N. (2013). MUET as a predictor of academic achievement in ESL teacher education. GEMA Online TM Journal of Language Studies, Vol. 13(1), 99-111.

Kong, J., Powers, S., Starr, L. \& Williams, N. (2012). Connecting English language learning and academic performance: A prediction study. American Educational Research Association, 1-22.

Moon, T. S. \& Siew, H. O., (2004). A study on the factors that impact on the academic performance of the computer science and the information technology students in University of Malaya. CMU Journal, Vol. 3(2), 169.

Nopiah, M. Z., Nur Azilah, I., Nuraini, K., Shahrum, A. \& Mohd Marzuki, M. (2011). MUET score and loading hour: An analysis on the relationship towards academic performance. Procedia Social and Behavioural Sciences. Vol. 18, 103-109.

Rethinasamy, S. \& Chuah, K. M. (2011). The Malaysian University English Test (MUET) and its use for placement purposes: A predictive validity study. Electronic Journal of Foreign Language Teaching, Vol. 8(2), 234-254.

Stephen, D. F., Welman, J. C. \& Jordaan, W. J. (2004). English language proficiency as an indicator of academic performance at a tertiary education. Journal of Human Resource Management, Vol. 2(3), 42-53.

Wilson, J. \& Komba, S. C (2012). The link between English language proficiency and academic performance: A pedagogical perspective in Tanzania secondary schools. World Journal of English Language, Vol. 2(4), 1-10. 